\title{
Laser cladding of Inconel 625-based composite coatings
}

\section{Keywords:}

laser cladding; composite coatings; Inconel 625

\begin{abstract}
Inconel 625-based composite coatings reinforced by $\mathrm{WC}$ and $\mathrm{Cr}_{3} \mathrm{C}_{2}$ particles have been produced via a diode laser cladding process. The effect of heat input level and morphology of the reinforcing particles on the degree of their dissolution has been established. Additionally, the influence of the morphology of the reinforcing particles on the erosive wear behaviour of the coatings was studied.
\end{abstract}

\section{Introduction}

MMC (Metal Matrix Composite) composites, consisting of a nickel-based matrix and a ceramic reinforcing phase $(\mathrm{RP})$, are an important group of materials used for the production of surface layers with high resistance to erosive wear [ $1 \div 3$ ]. The use of the Inconel 625 nickel matrix and the thermally stable RP, in particular $\mathrm{Cr}_{3} \mathrm{C}_{2}$ chromium carbide, additionally leads to obtaining $\mathrm{MMC}$ coatings having application potential under conditions of erosive and corrosive wear at elevated temperature [4,5].

The quality of the deposited ex-situ MMC coatings depends directly on the degree of dissolution of the RP particles in the liquid metal of the molten pool during the cladding process. Dissolution of RP particles in the molten pool leads to the formation of secondary precipitates in the matrix of the coating, which results in both deterioration of wear resistance of the coatings, as well as increasing their tendency to cracking $[6,7]$. Thus, the heat input of the cladding of ex-situ MMC composite layers has a direct effect on the RP content in the coating as well as the microstructure and mechanical properties of the matrix material, and consequently on the wear resistance of the coating.

The laser beam thanks to the high power density, reaching up to $10^{8} \mathrm{~W} / \mathrm{cm}^{2}$, and its precise control, unattainable by using other welding heat sources, such as plasma arc, ensures the minimum heat input. The rate of cooling of the liquid metal in the pool, during laser cladding of MMC composite coating, reaching even $10^{6} \mathrm{~K} / \mathrm{s}$, causes the $\mathrm{RP}$ particles to dissolve to a limited extent in the metal matrix of the coating. Laser cladding is a relatively modern technology of applying composite MMC layers, which provides special functional properties of the coatings and a minimum dilution levels $[8,9]$.
High power diode laser with direct beam transmission to the work surface (HPDDL - High Power Direct Diode Laser), thanks to the rectangular focus of the laser beam and an even distribution of power density on its surface ("top hat" profile) is the ideal heat source in the cladding process of the MMC composite of ex-situ type [10].

The article presents the results of research on the development of Inconel 625 based MMC coatings high resistance to erosive wear. Particular attention was devoted to determining the effect of RP morphology on the erosion resistance of the coatings. The presented research results relate to the surfacing process using the HPDDL diode laser.

\section{Materials and research methodology}

As an additional material for cladding, powder mixtures based on Inconel 625 nickel alloy were used, with chemical composition of (by weight): $0.02 \% \mathrm{C}, 19.6 \% \mathrm{Cr}, 5.8 \% \mathrm{Mo}$, $1.6 \% \mathrm{Fe}, 3.9 \% \mathrm{Nb}, 0.1 \% \mathrm{Al}, 0.4 \% \mathrm{Si}, 0.15 \% \mathrm{Ti}$ and $\mathrm{Ni}$ base, with particles of $\mathrm{Cr}_{3} \mathrm{C}_{2}$ chromium carbide and tungsten carbide WC. In order to determine the effect of RP particle morphology on the erosion resistance of the coatings, the tests were performed using solid spherical and irregular (crushed) WC particles as well as porous particles of $\mathrm{Cr}_{3} \mathrm{C}_{2}$ chromium carbide. The grain size of the WC particles was in the range of $100 \div 200 \mu \mathrm{m} . \mathrm{Cr}_{3} \mathrm{C}_{2}$ particles with $60 \%$ open porosity had a grain size in the range of $45 \div 70 \mu \mathrm{m}$.

The cladding tests were carried out on an automated stand equipped with a HPDDL Rofin DL 020 diode laser with a rectangular focus of the beam and a focal point dimensions 
of $1.5 \times 6.6 \mathrm{~mm}$ and an even distribution of the power density on its surface (Fig. 1). The HPDDL laser beam is focused on the upper surface of AISI 304L steel plates, $10.0 \mathrm{~mm}$ thick, prepared for surfacing by grinding and chemical cleaning. The cladding tests were carried out towards the short side of the rectangular focus of the laser beam using a powder feed system to ensure uniform distribution of the powder particles on the focus of the laser beam (Fig. 2). To protect the molten pool and the powder stream against oxidation, an argon blowing intensity of $8.0 \mathrm{I} / \mathrm{min}$ was applied through a cylindrical nozzle, aligned coaxially with the powder feed nozzle. The quality of clads was determined on the basis of metallographic and erosion tests (according to the ASTM-G76 standard), as well as microhardness measurements. The erosion resistance of the MMC coatings was compared with the erosion resistance of the Inconel 625 metallic coatings.

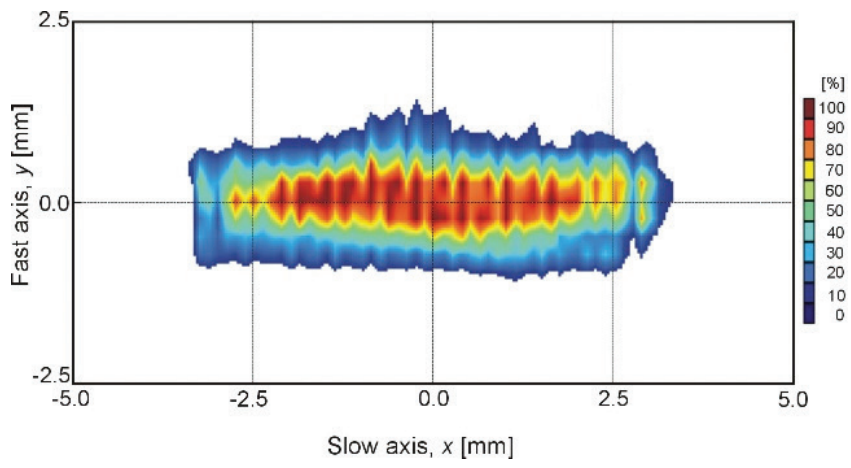

Fig. 1. 2D beam profile of the used HPDD laser in the focal plane

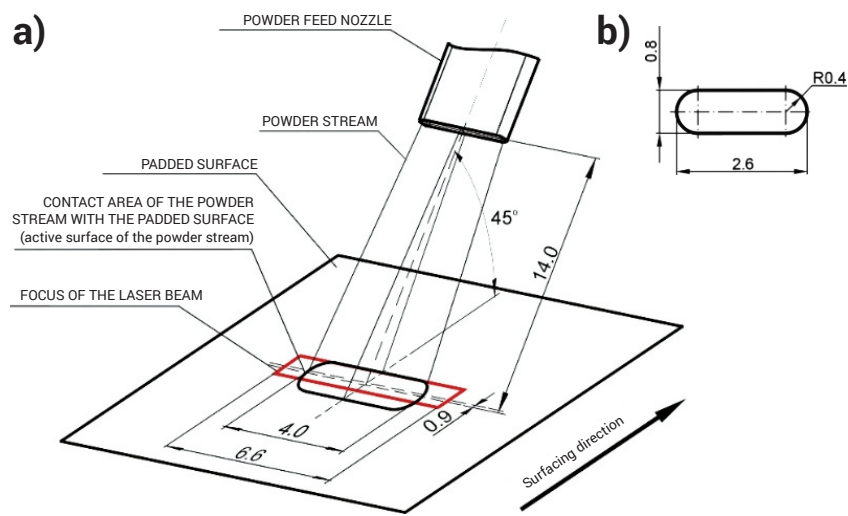

Fig. 2. Diagram showing: a) the alignment of the powder injection nozzle relative to the laser beam spot; $b$ ) the geometry of the powder injection nozzle opening used

\section{Test results analysis}

The macrostructure of single-pass composite clads containing RP in the form of solid and porous particles are presented in Figures 3 and 4 . The use of solid WC particles, both spherical and irregular, makes it possible to obtain clads with an uniform RP distribution and its fraction up to approx. $60 \%$ by volume, with a minimum degree of dissolution ( $2 \%$ vol.), Figures $5 \mathrm{a}$ and 7 . For porous RP particles, increasing the proportion of $\mathrm{Cr}_{3} \mathrm{C}_{2}$ particles in the powder above 40 wt.\%. resulted in a significant porosity of clads. As a consequence, homogeneous $\mathrm{MMC}$ layers reinforced with porous $\mathrm{Cr}_{3} \mathrm{C}_{2}$ particles contained up to approx. $36 \%$ RP by volume (Fig. $5 \mathrm{~b}$ and Fig. 9). All tested types of MMC layers allowed making multi-bead pads with uniform RP distribution and the dilution at the level of $4 \div 5 \%$ (Fig. 6).
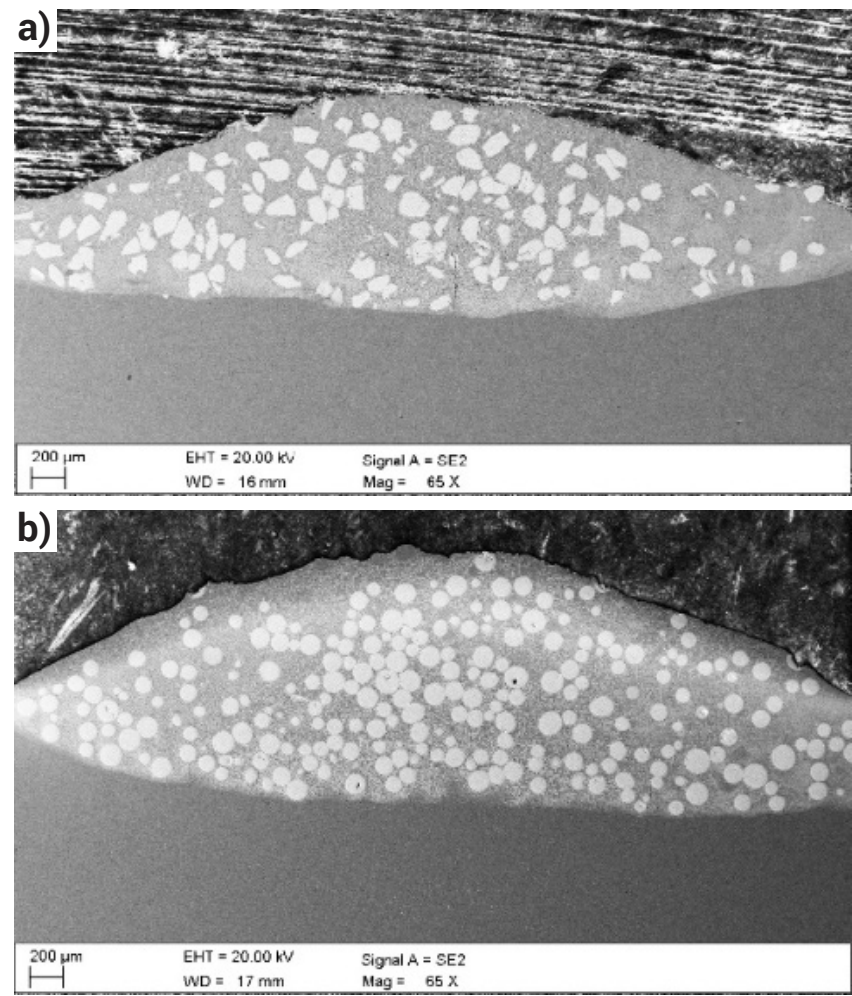

Fig. 3. Macrostructures of single-pass clads produced using a powder mixture containing 60 vol.\% of WC particles having a) angular; b) spherical shape. The heat input of $300 \mathrm{~J} / \mathrm{mm}$

The degree of dissolution of RP particles depends directly on their size, fraction in the powder for cladding and the heat input. The results of the tests presented in [6] indicate that, with given heat input, the degree of dissolution of RP particles decreases with the increase of their size. In turn, with a given granulation of RP particles, the increase in the heat input increases the degree of dissolution of RP in the matrix, which leads to an increase in the fraction of secondary precipitates (type $\mathrm{M}_{6} \mathrm{C}$ for layers with WC and $\mathrm{Cr}_{7} \mathrm{C}_{3}$ for layers with $\mathrm{Cr}_{3} \mathrm{C}_{2}$ ) in the matrix, and consequently the increase in its hardness. In the case of WC reinforced layers, an increase in the heat input from 240 to $420 \mathrm{~J} / \mathrm{mm}$ increased the hardness of the matrix from 300 to $500 \mathrm{HV}$. In addition, the enrichment of the molten pool with elements resulting from the dissolution of RP leads to the formation of secondary phases in the transition zone between RP and the matrix (Fig. 8). The spherical shape of the RP particles, minimizing the area of contact with liquid metal in the molten pool, ensures a lower degree of dissolution of the $\mathrm{RP}$ than in the case of an irregular shape, given a heat input and particle granulation (Fig. 5a). In turn, porous $\mathrm{Cr}_{3} \mathrm{C}_{2}$ particles have the highest tendency to dissolve in the liquid metal of the molten pool, which results both from the low thermal capacity of the porous structure as well as the low melting point of the $\mathrm{Cr}_{3} \mathrm{C}_{2}$ phase. As a consequence, the range of heat input, ensuring both infiltration of the porous structure of $\mathrm{Cr}_{3} \mathrm{C}_{2}$ particles with liquid metal in the pool (Fig. 9), as well as their minimal dissolution is very narrow (Fig. $5 \mathrm{~b}$ ).

Erosive wear tests of the coatings rein-forced by WC, made at the lowest heat input $(240 \mathrm{~J} / \mathrm{mm})$, showed a typical mechanism of erosive wear for MMC materials, with the RP particle shape having a significant effect on the wear mechanism and, consequently, the erosion resistance of the coatings. The erosion resistance of the coatings reinforced with spherical and irregular WC particles was 2.5 and more than 4 times higher than the metallic Inconel 625 coatings at an angle of incidence of the erodent of $15^{\circ}$. 

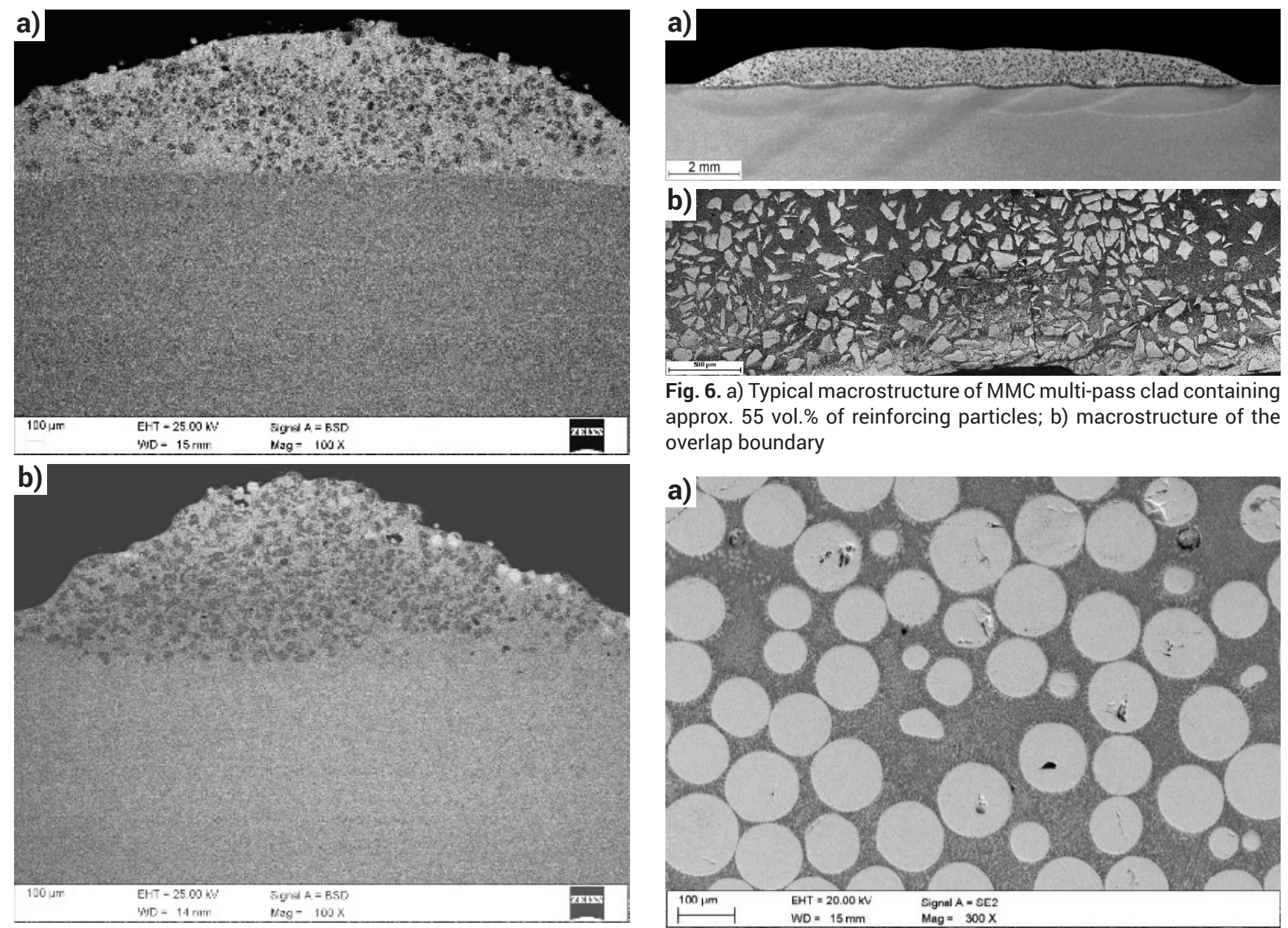

Fig. 6. a) Typical macrostructure of MMC multi-pass clad containing approx. 55 vol.\% of reinforcing particles; b) macrostructure of the overlap boundary

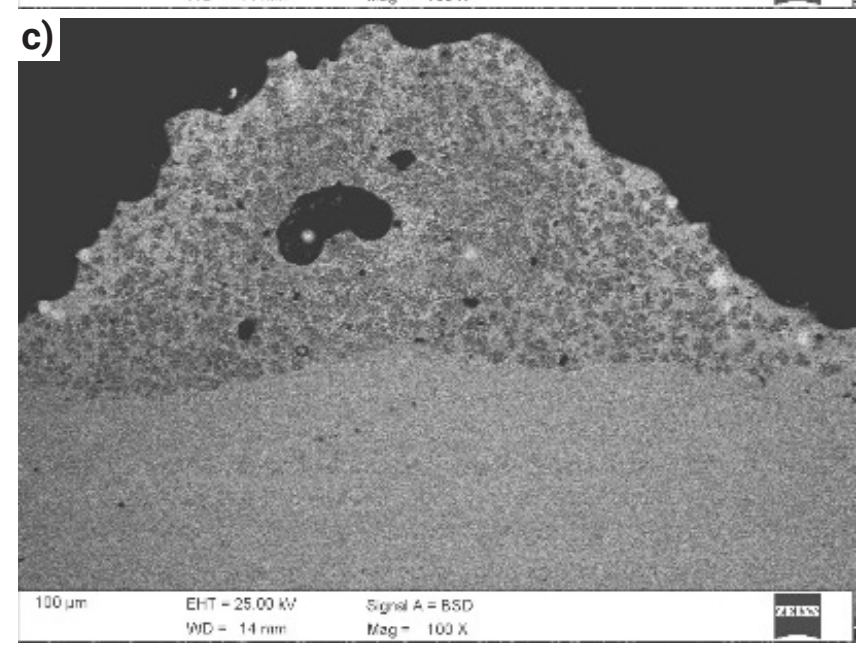

Fig. 4. Macrostructures of single-pass clads produced using powder mixtures of Inconel 625 and porous $\mathrm{Cr}_{3} \mathrm{C}_{2}$ particles prepared at the weight ratio of: a) $70: 30$; b) 60:40; c) 50:50. The heat input of $192 \mathrm{~J} / \mathrm{mm}$
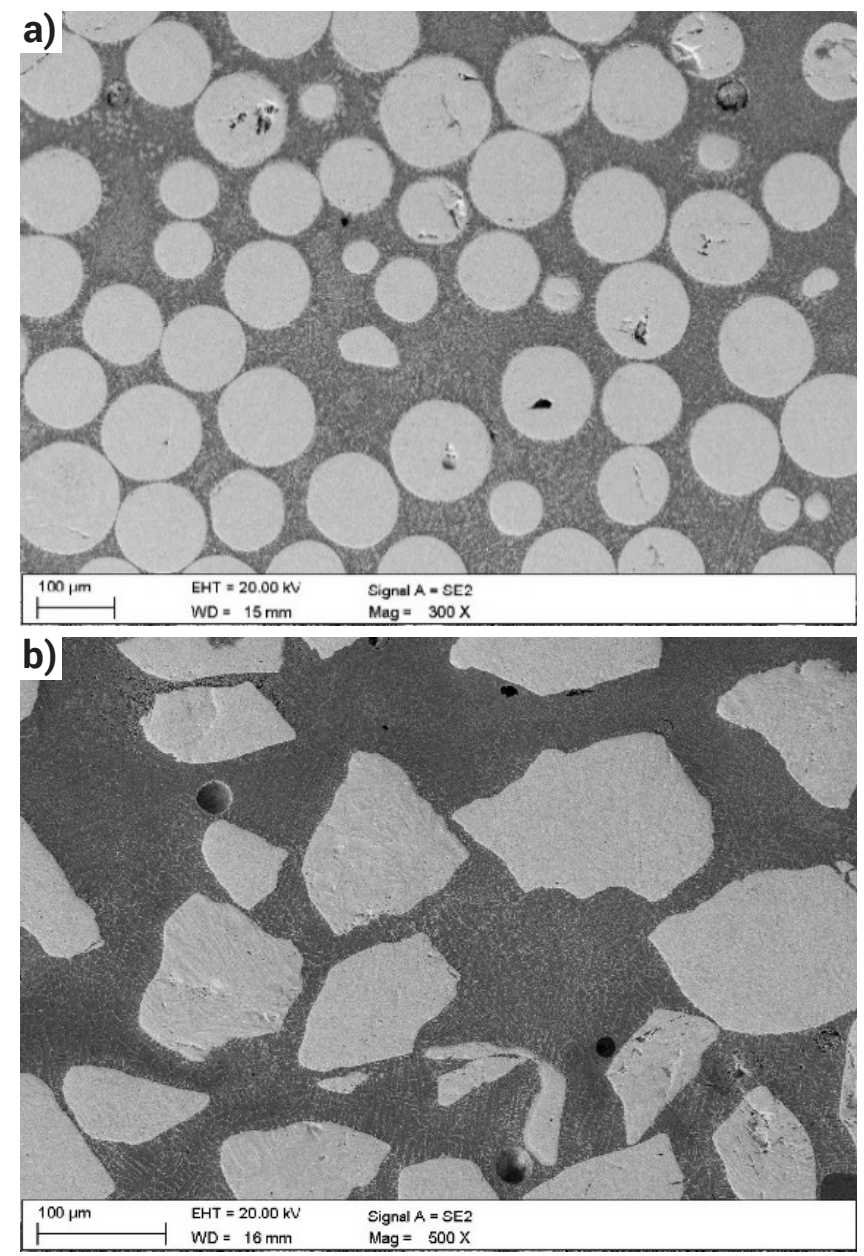

Fig. 7. Microstructure of coatings produced using a powder mixture containing 60 vol.\% of WC particles having: a) spherical and b) angular shape under the heat input of $240 \mathrm{~J} / \mathrm{mm}$
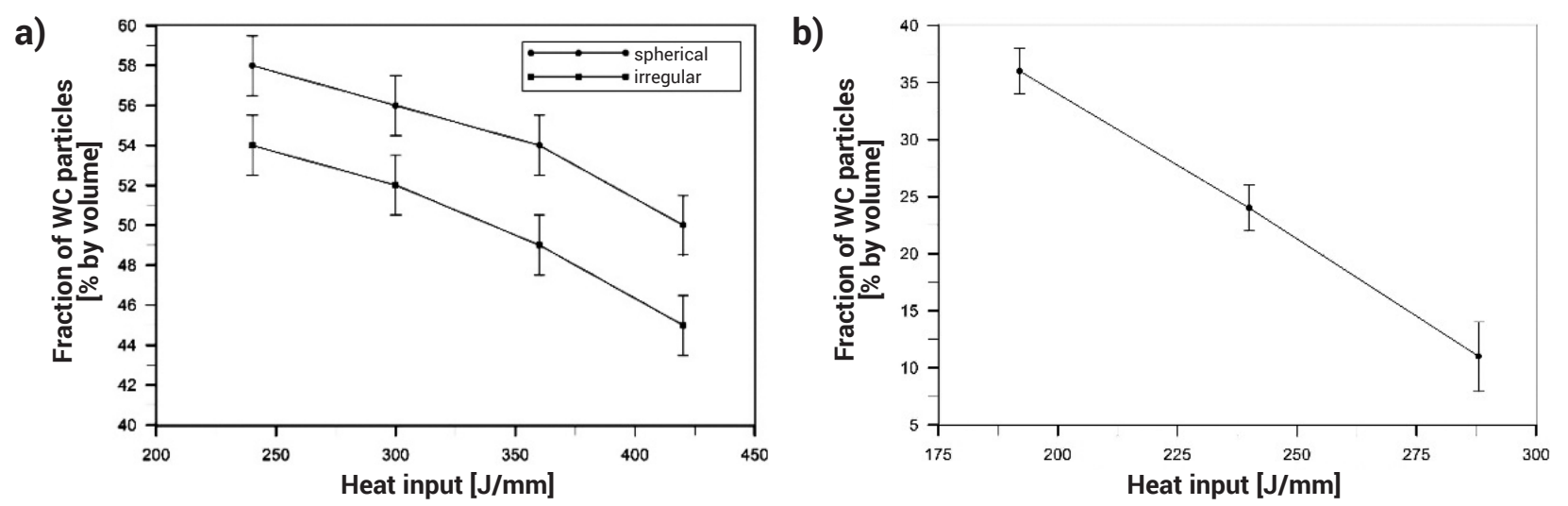

Fig. 5. Effect of the heat input level on the fraction of reinforcing particles in the coatings produced using: a) powder mixture with 60 vol.\% of WC; b) powder mixture with $40 \mathrm{wt} . \%$ of $\mathrm{Cr}_{3} \mathrm{C}_{2}$ 

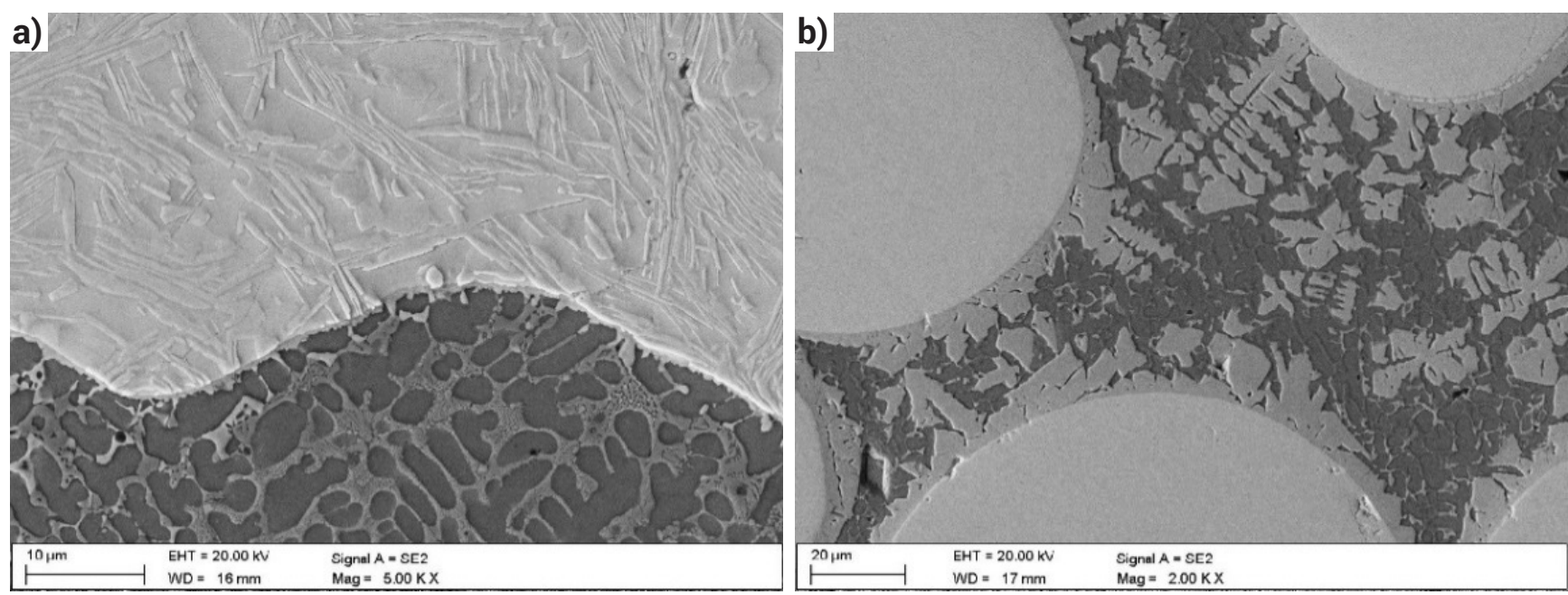

Fig. 8. Typical microstructure of the transition region between $\mathrm{WC}$ and matrix in the coatings produced at the heat input of a) $240 \mathrm{~J} / \mathrm{mm}$; and b) $420 \mathrm{~J} / \mathrm{mm}$
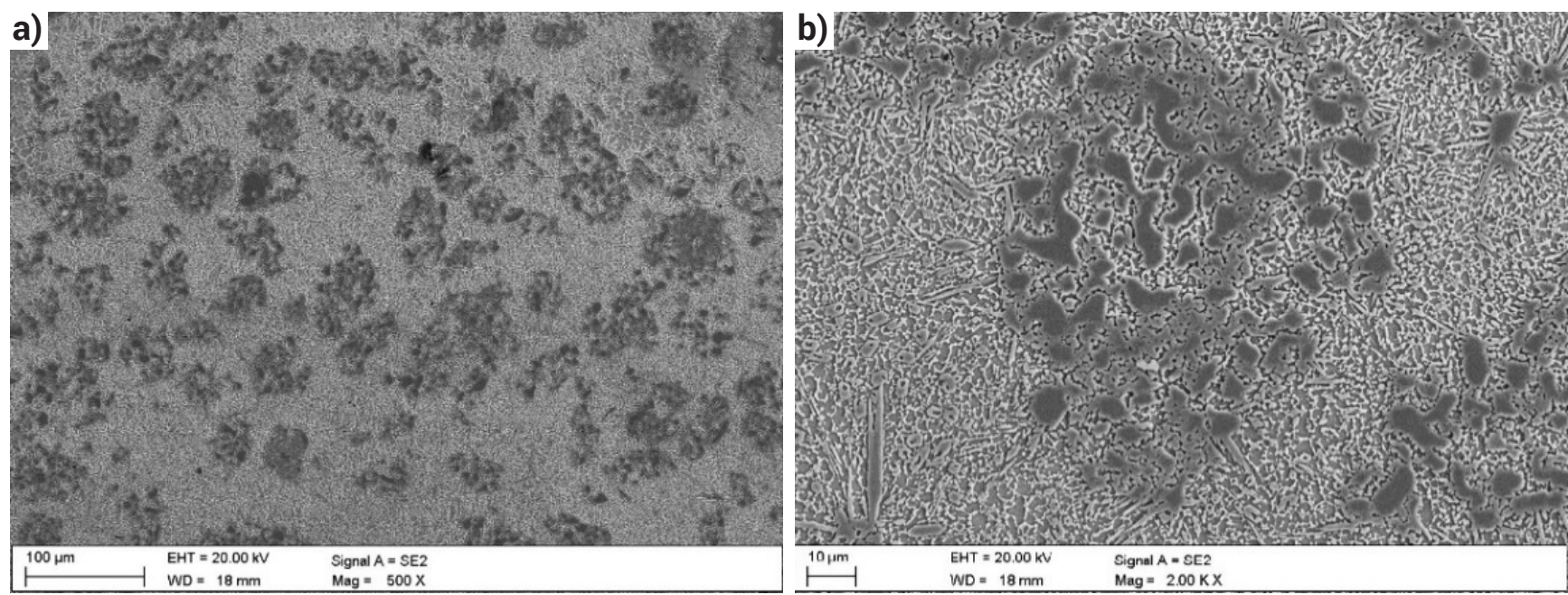

Fig. 9. a) Microstructure of the coating reinforced by porous $\mathrm{Cr}_{3} \mathrm{C}_{2}$ particles; b) image showing the porous particle fully infiltrated by the matrix alloy
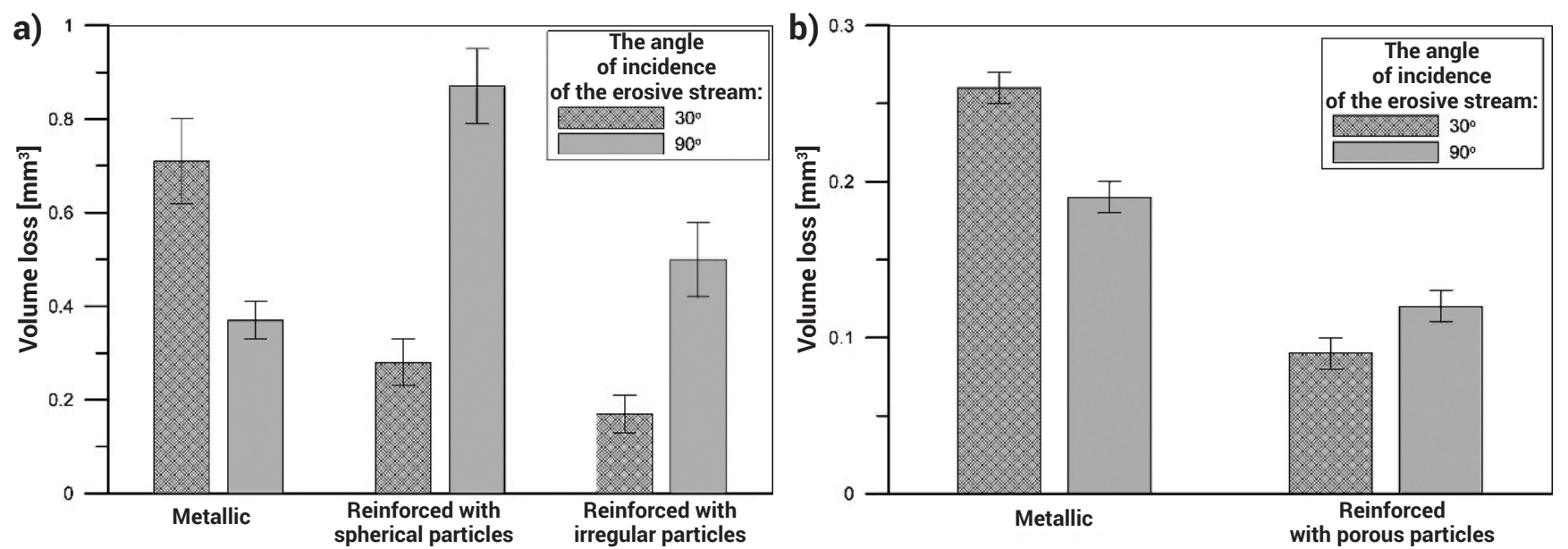

Fig. 10. Comparison of results of the erosion testing for the composite and metallic Inconel 625 coatings: a) coatings reinforced by WC (erodent impingement velocity of $70 \mathrm{~m} / \mathrm{s}$ ); b) coatings reinforced by $\mathrm{Cr}_{3} \mathrm{C}_{2}$ (erodent impingement velocity of $40 \mathrm{~m} / \mathrm{s}$ )

In turn, at an angle of $90^{\circ}$, the erosion resistance of the Inconel 625 metallic coatings was $35 \%$ and more than twice as high as the composite coatings reinforced with irregular and spherical particles (Fig. 10a). Observations of the erosive surface of the coatings made on the SEM microscope (Fig. 11 and 12) confirmed the occurrence of two mechanisms of wear typical for MMC materials. One is responsible for the loss of the soft matrix material, while the other leads to the loss of hard RP particles. The surface of the composite coating is subject to wear as a result of cracking and chipping of WC particles, as well as micro-cutting of the matrix material. The contribution of both of those mechanisms to the wear of the coatings depends on the angle of incidence of the erodent. Intensive cracking and chipping of RP is the main cause of low erosive resistance of MMC coatings at an angle of incidence of the erodent of $90^{\circ}$.

It is worth noting that the analysis of the results of erosive research indicates a much more intense loss of spherical WC particles than irregular ones. This is directly due to a much better mechanical anchorage in the matrix of irregular RP 

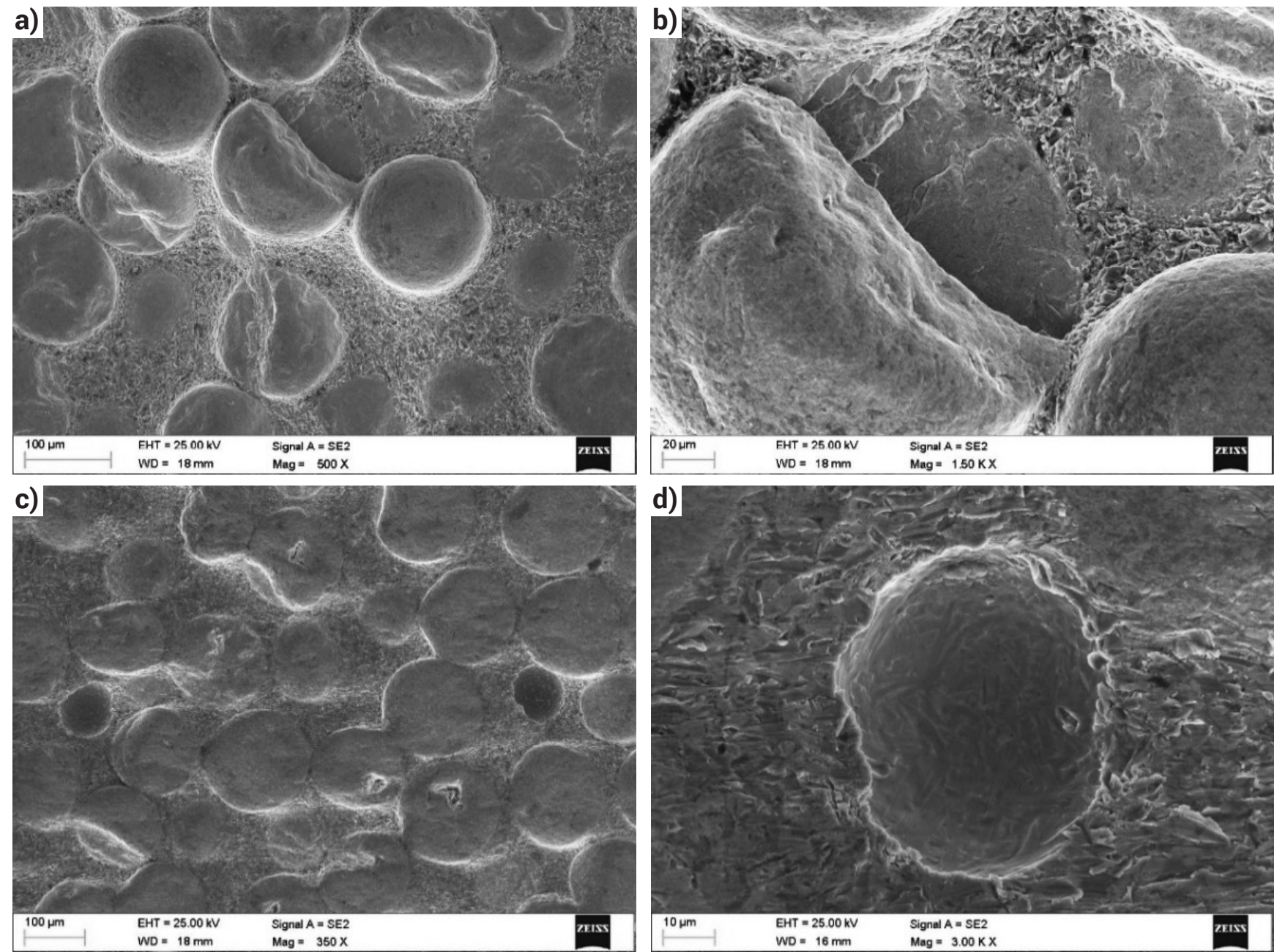

Fig. 11. SEM images of the worn surface of the composite coatings reinforced by spherical WC particles at the impingement angle of: a,b) $90^{\circ}$ and c,d) $30^{\circ}$
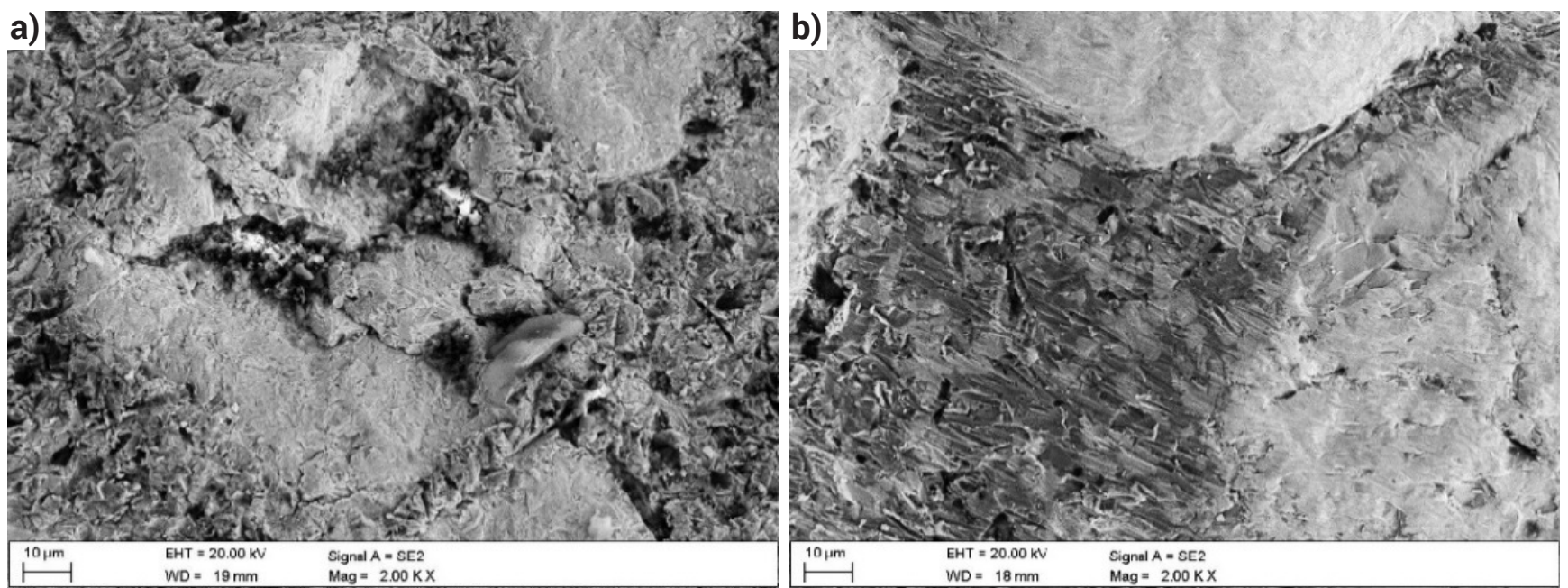

Fig. 12. SEM images of the worn surface of the composite coatings reinforced by angular WC particles at the impingement angle of: a) $90^{\circ}$ and b) $30^{\circ}$

particles compared to spherical ones. Irregular RP particles, even after the occurrence of cracks, persist on the surface being consumed, ensuring its erosion resistance (Fig. 12). The regular shape and smooth surface of the spherical particles limits their cracking, however, it intensifies the removal of the adjacent matrix material (Fig. 11). In this case, the erodent particle falling at an angle of $90^{\circ}$, by contacting the spherical $\mathrm{RP}$ particle, moves tangentially to its surface by micro-cutting the adjacent matrix. After a certain time, the spherical particle without cracks (no signs of wear) breaks off due to lack of support (Fig. 11a and 11b), which leads to the removal of relatively large pieces of RP and, as a consequence, low erosive resistance of the coating. Furthermore, as shown in Figures $11 \mathrm{c}$ and d, at an angle of incidence of the erodent of $15^{\circ}$, the regular and smooth surface of the spherical particles leads to decohesion at the RP/matrix boundary.

In contrast to coatings reinforced with RP solid particles, coatings containing porous $\mathrm{Cr}_{3} \mathrm{C}_{2}$ particles showed significantly higher erosion resistance than the metal layers of Inconel 625 at both erodent incidence angles tested (approximately $60 \%$ and 3 times at an angle of $90^{\circ}$ and $15^{\circ}$ )(Fig. 10b). Comparable erosion resistance of coatings reinforced 
with porous $\mathrm{Cr}_{3} \mathrm{C}_{2}$ particles at both extreme erosion conditions is not a typical feature of MMC materials. The analysis of worn surfaces, at both angles of incidence of the erodent, showed no clear signs of RP cracking and a large range of wear mechanism typical for plastic materials [10]. Considering that the erosion resistance at the angle of incidence of the erodent of $90^{\circ}$ is directly dependent on the material's ability to absorb the kinetic energy of the erodent particles through plastic deformation, the above-mentioned special properties of coatings reinforced with porous $\mathrm{Cr}_{3} \mathrm{C}_{2}$ particles should be attributed to the specific microstructure of these coatings, which provide them with relatively high plasticity. In the case of these layers, the RP particle has a hybrid structure consisting of a ceramic backbone filled with a plastic matrix material (Fig. 9b), which ensures its much greater ability to absorb the kinetic energy of the erodent than in the case of solid particles. In addition, the hybrid structure provides excellent mechanical anchoring of RP in the matrix and significantly limits the cracking range of the ceramic skeleton, which leads to chipping out very small pieces of RP (Fig. 13).
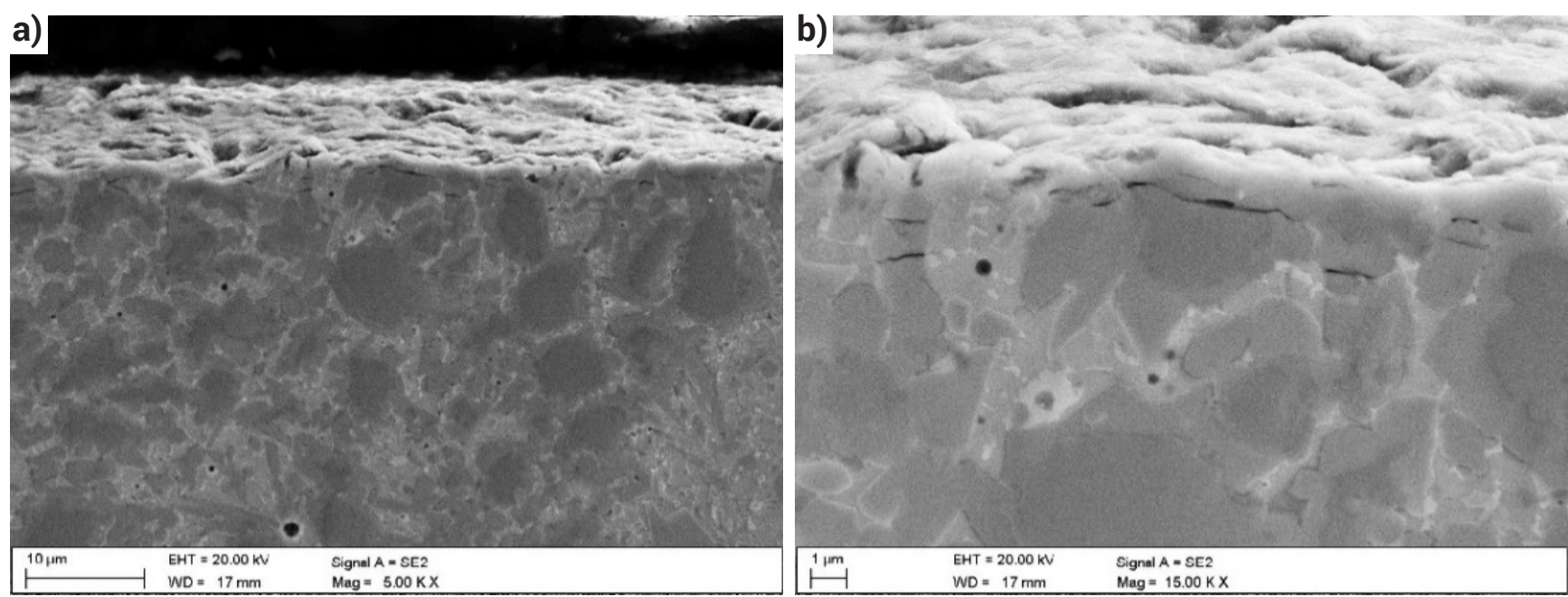

Fig. 13. a) Micrographs of the traverse section of the composite coating reinforced by porous $\mathrm{Cr}_{3} \mathrm{C}_{2}$ particles eroded at $90^{\circ}$ impingement angle; b) a detail from showing sub-surface cracks of the reinforcing particles

\section{Conclusions}

HPDDL diode laser cladding, thanks to an even distribution of power density on the surface of a rectangular focus of the laser beam, enables application of ex-situ MMC coatings with the minimum degree of RP dissolution, uniform RP distribution in the matrix and minimal dilution level. The spherical shape of the RP limits the degree of its dissolution in the molten pool.

Due to the better mechanical interlocking of RP in the metallic matrix, the coatings reinforced with irregular WC particles show a significantly higher erosive resistance compared to the coatings reinforced by spherical WC particles. The coatings reinforced with porous $\mathrm{Cr}_{3} \mathrm{C}_{2}$ particles, due to the unique structure of $\mathrm{RP}$, show a comparable erosion resistance at the incidence angles of $30^{\circ}$ and $90^{\circ}$.

\section{References}

[1] L. St-Georges, Development and characterization of composite Ni-Cr+WC laser cladding, Wear (2007), vol. 263, 562-566.

[2] J. Nurminen, J. Nakki, P. Vuoristo, Microstructure and properties of hard and wear resistant MMC coatings deposited by laser cladding, Int. Journal of refractory Materials \& Hard Materials (2009), vol. 27, 472-478.

[3] J. Przybyłowicz, J. Kusiński, Structure of laser cladded tungsten carbide composite coatings, Journal of Materials Processing Technology (2001) vol. 109, 154-160.

[4] R. Dooley, E. Wiertel, A survey of erosion and corrosion resistant materials being used on boiler tubes in waste to energy boilers, Proceedings of the 17the Annual North American Waste-to-Energy Conference, NAWTEC17, Chantilly, Virginia, USA (2009).

[5] S.H.Lee, N.J. Themelis, M.J. Castalidi, High-temperature corrosion in waste-to energy Boilers, Journal of Thermal Spray Technology (2007), vol. 16(1), 1-7
[6] D. Janicki, High Power Diode Laser Cladding of Wear Resistant Metal Matrix Composite Coatings, Solid State Phenomena (2013), vol. 199, 587-592.

[7] D. Janicki, M. Musztyfaga-Staszuk, Direct Diode Laser Cladding of Inconel 625/WC Composite Coatings, Strojniški vestnik, Journal of Mechanical Engineering (2016), vol. 62(6), 363-372.

[8] J. Zhong, W. Liu, K. Yao, J.C. Goussain, C. Mayer, A. Backer, Microstructural evolution in high power laser cladding of Stellite $6+W C$ layers, Surface and Coatings Technology (2002), vol. 157, 128-137.

[9] C.P. Poul, H. Aleohammad, E. Toyserkani, A. Khajepour, S. Corbin: Cladding of WC - 12 Co on low carbon steel using a pulsed N:YAG laser, Materials Science and Engineering A (2007), vol. 464, 170-176.

[10] D. Janicki, Laser cladding of Inconel 625-based composite coatings reinforced by porous chromium carbide particles, Optics and Laser Technology (2017), vol.94, 6-1. 